\title{
Inhibitory effects of msFGFR2c on the epithelial-to- mesenchymal transition of AE2 cells in pulmonary fibrosis
}

\author{
Guo Jieming $\cdot$ Chuan Liu $\cdot$ Yin Yang $\cdot$ Shanyi Mo $\cdot$ Xuesong Yang $・$ \\ Ju Wang (i)
}

Received: 8 October 2019/Accepted: 26 February 2020/Published online: 4 March 2020

(C) The Author(s) 2020

\begin{abstract}
In interstitial fibrosis, alveolar epithelial type II (AE2) cells fail to repair damaged epithelium. However, whether this dysfunction is related to fibroblast growth factor (FGF) signal pathway and how it affects the fibrotic process remains unclear. In our study, the medium of the human foetal lung fibroblast cell line MRC-5 (Med) can induce epithelial-to-mesenchymal transition (EMT) in AE2 cells, we also found that TGF- $\beta$ in Med can induce FGF-2 and CTGF expression in AE2 cells. TGF- $\beta$ or CTGF exposure trigger a FGFR2 subtype $\mathrm{b}$ to $\mathrm{c}$ transition which can be supressed by siRNA-CTGF. All together, since FGFR2IIIc have the highest affinity with FGF-2 in all of the FGFRs, we indicate the activation of FGF2 signal pathway was induced by TGF- $\beta$, which is the key component of Med Here, we also find the inhibitory effect of msFGFR2c (S252W mutant of soluble FGFR2IIIc extracellular domain) on
\end{abstract}

G. Jieming

Tai Shan College, Shandong University, Jinan 250000, China

C. Liu $\cdot$ Y. Yang $\cdot$ S. Mo $\cdot$ J. Wang $(\bowtie)$

Institute of Biomedicine, National Engineering Research Center of Genetic Medicine, Jinan University,

Guangzhou 510632, China

e-mail:wangju168899@qq.com

\section{Yang}

Department of Pediatrics and Neonatology, Institute of Fetal-Preterm Labor Medicine, The First Affiliated

Hospital, Jinan University, Guangzhou 510630, China
EMT of mouse primary AE2 cells in pulmonary fibrotic process. In a bleomycin-induced mouse pulmonary fibrosis model, msFGFR2c alleviate pulmonary fibrosis and suppress the decrease in proSPC levels. Thus, msFGFR2c can inhibit EMTinduced fibrosis of AE2 cells via FGF-2 signal and AE2 cells is suggested to play an important role in the lung fibrotic process.

Keywords CTGF $\cdot$ FGF-2 $\cdot$ msFGFR2c $\cdot$ Pulmonary fibrosis - TGF- $\beta$

\section{Introduction}

Pulmonary fibrosis is a respiratory disease characterized by excessive hyperplasia of connective tissues, leading to thickening of the pulmonary alveolar septa, scar formation in lungs, and progressive and serious breathing difficulty (Raghu et al. 2016; Zhang et al. 2012). Idiopathic pulmonary fibrosis (pulmonary fibrosis of unknown origin) (Raghu et al. 2016; Zhang et al. 2012) is a rare disease (Raghu et al. 2006) with poor prognosis and survival time of 2.5-3.5 years after diagnosis (Demedts and Costabel 2002; Society AT 2000). Mammalian alveolar epithelial cells comprise alveolar epithelial type I (AE1) and type II (AE2) cells. AE2 cells synthesize and secrete phospholipidrich pulmonary surfactants, including SPA, SPB, SPC, 
and SPD, for preventing alveolar collapse by lowering alveolar surface tension (Zhang et al. 2012; Whitsett et al. 2010), a vital factor for maintenance of alveolar stability and functions. Furthermore, when AE1 cells are damaged, AE2 cells can proliferate and differentiate into AE1 cells to maintain alveolar wall integrity (Tsuji et al. 2009; Miyake et al. 2007). Persistence of pathogen-related chronic pulmonary injury reduced the differentiation of AE2 to AE1 cells and induces the secretion of various profibrogenic cytokines from AE2 cells that promote pulmonary fibrosis (Kim et al. 2006). However, the precise role of this dysfunction in the fibrotic process is unclear.

Transforming growth factor $\beta$ (TGF- $\beta$ ) is recognized as the most important factor among profibrogenic cytokines (Yang et al. 2014), and it is mainly synthesized and secreted by alveolar macrophages and epithelial cells (Lee et al. 1997). Connective tissue growth factor (CTGF), another profibrogenic cytokine, plays an important role in the formation of pulmonary fibrosis under tissue damage (Robinson et al. 2012); it is expressed at extremely low concentrations under normal conditions and is overexpressed by specific stimuli (e.g., hypoxia or TGF- $\beta$ ) (Yang et al. 2014; Han et al. 2008). Numerous studies have attributed this increased CTGF production to stress fibre production, extracellular matrix protein accumulation, and myofibroblast differentiation (Robinson et al. 2012; Han et al. 2008), and indicate that CTGF is a key mediator contributing to progression of interstitial pulmonary fibrosis.

Previously, we reported a S252W mutant sFGFR2IIIc (msFGFR2) that was bacterially expressed and subsequently renatured ( $\mathrm{Yu}$ et al. 2012). The binding affinity of FGFR2IIIc for fibroblast growth factor-2 (FGF-2) is the highest as it is the most appropriate receptor for FGF-2 (Powers et al. 2000). We also reported that FGF-2 antibody could almost completely inhibit the $\alpha$-SMA increase induced by TGF- $\beta$, which suggested that FGFR2c might play major role in TGF-beta induced EMT in the AE2 cells since FGFR2c is the most compatible receptor of FGF2 (Wang et al. 2012). Besides, TGF- $\beta$ activated the FGF signalling pathway in fibroblasts to promote the fibrotic process, and that wild-type and mutant sFGFR2c (wsFGFR2c and msFGFR2c, respectively) markedly inhibited fibrosis by blocking FGF signal (Robinson et al. 2012; Anderson et al. 1998; Byron and Pollock 2009; Haugsten et al. 2010; Ibrahimi et al.
2004; Wang et al. 2011; Katoh and Katoh 2009; Matsuda et al. 2012). However, the role of FGF signaling in AE2 cell-mediated regulation of pulmonary fibrotic formation is unclear. In this study, we attempted to understand the mechanism on the inhibitory effect of msFGFR2c in this process in vitro and in vivo. Our findings provide insights into the potential application of msFGFR2c in the development of therapies for pulmonary fibrosis.

\section{Materials and methods}

msFGFR2c expression, renaturation, and purification

We prepared msFGFR2 according to our previously published report (Wang et al. 2011). Briefly, the DNA region from D2 to D3 of the FGFR2IIIc isoform (amino acids 147-366 of hBEK) was amplified from the cDNA, and the S252W mutation was introduced using the splice overlap polymerase chain reaction (PCR) method. The gene fragments were cloned into the $\mathrm{pET} 3 \mathrm{c}$ vector and expressed in Escherichia coli. Bacteria were collected and lysed, and inclusion bodies were refolded and purified. msFGFR2c with more than $95 \%$ purity was harvested using heparin affinity chromatography (GE, Fairfield, CT, USA) (Yu et al. 2012).

\section{Transfection with siRNA}

AE2 cells were transfected with CTGF siRNA or negative control siRNA (GenePharma Co. Ltd. Shanghai, China) using Lipofectamine 2000 transfection reagent (Invitrogen, Carlsbad, CA, USA) in serum-free medium according to the manufacturers' instructions. After $48 \mathrm{~h}$ transfected cells were treated with $4 \mathrm{ng} / \mathrm{ml}$ recombinant TGF- $\beta$ (R\&D Systems China Co. Ltd., Shanghai, China) for a further $24 \mathrm{~h}$ before proteins were extracted for western blot analysis. The sequence of siRNAs targeting the mouse CTGF gene are shown as follow, sense si-CTGF-1: $5^{\prime}$ GGUCAAGCUGCCCGGGAAATT- $3^{\prime}$; antisense siCTGF-1: 5'-UUUCCCGGGCAGCUUGACCTT-3'; sense si-CTGF-2: 5'-CCCGGGUUACCAAUGACA ATT-3'; antisense si-CTGF-2: 5'-UUGUCAUUGGUAACCCGGGTT-3'; sense si-CTGF-3: 5'-CCUG UCAAGUUUGAGCUUUTT- ${ }^{\prime}$; antisense si-CTGF- 
3: 5'-AAAGCUCAAACUUGACAGGTT-3'; sense si-CTGF-Negative control: 5'-UUCUCCGAACGUGUCACGUTT- $3^{\prime}$; antisense si-CTGF-Negative control: 5'ACGUGACACGUUCGGAGAATT-3'.

\section{Cell lines}

Human fetal lung fibroblast cells (MRC-5) and mouse primary AE2 cells were purchased from GuangZhou Jennio Biotech Co. Ltd. (Guangzhou, China), respectively. AE2 cells were cultured in DMEM containing $10 \%$ fetal bovine serum (FBS) (Invitrogen, Carlsbad, CA, USA), $1 \%(\mathrm{v} / \mathrm{v})$ insulin-transferrin-selenium (Sigma, St. Louis, MO, USA), and epidermal growth factor (10 ng/ml; Sigma). MRC-5 cells were cultured in DMEM containing 10\% fetal bovine serum (Invitrogen, Carlsbad, CA, USA).

\section{Experimental animals}

C57BL/6 mice were obtained from the Medical Experimental Animal Centre of Guangdong Province (Guangzhou, China). Pulmonary fibrosis was induced in 10-week-old female mice by intratracheal instillation of bleomycin (BLM; Hisun Pharmaceutical Co. Ltd., Zhejiang, China) at $3 \mathrm{mg} / \mathrm{kg}$ body weight once in three days. The same amount of saline was intratracheally instilled for the control group. The experimental animals were randomly divided into four groups, namely, those treated with normal saline (control), BLM, or BLM + msFGFR2c. $30 \mu \mathrm{g}$ msFGFR2c each animal was intraperitoneally injected daily beginning on day 4 , and the treated animals were scarified to obtain lung tissue on day 1, 10, 20, and 30 $(n=3)$. All animal experiments were performed in accordance with the procedures of the Ethical Committee for Animal Experimentation, Jinan University.

Western blot analysis

Antibodies against the following proteins were used: $\alpha$-SMA (Millipore, MA, USA), $\beta$-actin, CTGF (Santa Cruz Biotechnology, CA, USA), Prosurfactant Protein C (Abcam, Cambridge, UK), N-cadherin, E-cadherin. Horse radish peroxidase (HRP)-conjugated antimouse IgG and HRP-conjugated anti-rabbit IgG (Cell Signaling Technology, Danvers, MA, USA) were used as secondary antibodies. All primary antibodies were diluted 2000-fold and secondary antibodies were diluted 10,000-fold in 5\% bovine serum albumin (BSA).

RNA extraction and real-time quantitative PCR analysis

Total RNA was isolated from mouse lung AE2 cells using a TRIzol kit (Invitrogen) according to the manufacturer's instructions. First-strand cDNA synthesis and SYBR ${ }^{\circledR}$ Green qPCR assays were performed using a PrimeScript ${ }^{\mathrm{TM}} \mathrm{RT}$ reagent kit (Takara Bio Inc., Shiga, Japan). The specific primers used were: $\beta$-actin F: $5^{\prime}$-TGCAGTGGCAAAGTGGAGA TT-3' R: 5'-TTGAAGTCGCAGGAGACAACCT-3', FGFR1IIIb F: 5'-CGGGAATTAATAGCTCGGAT GC-3' R: 5'-TTGGTGCCGCTCTTCATCTT-3', FG FR1IIIc F: $5^{\prime}$-GGACTCTCCCATCACTCTGCAT-3' R: 5'-CCCCTGTGCAATAGATGATGATC-3', FGF R2IIIb F: 5'-GATAAATAGTTCCAATGCAGAA GTGCT-3' R: 5'-TGCCCTATATAATTGGAGACC TTACA-3', FGFR2IIIc F: 5'-GGATATCCTTTC ACTCTGCATGGT-3' R: 5'-TGGAGTAAATGGCT ATCTCCAGGTA- $3^{\prime}$. Reverse transcription and amplification reactions were performed using the Bio-Rad S1000TM and ABI 7000 (Applied Biosystems, Carlsbad, CA, USA) thermal cyclers, respectively. Gene expression levels were normalized to those of the housekeeping gene $\beta$-actin.

Enzyme-linked immunosorbent assay (ELISA)

MRC-5 and AE2 cells were seeded in $100 \mathrm{~mm}$ dishes at a density of $2 \times 10^{6} /$ dish and incubated in regular medium overnight; they were then placed in serumfree medium for $24 \mathrm{~h}$. FGF-2, CTGF or TGF- $\beta$ levels were detected using FGF-2, CTGF or TGF- $\beta$ ELISA kit (Quantikine ${ }^{\mathrm{TM}}$; R\&D Systems, Minneapolis, MN, USA) according to the manufacturer's instructions.

\section{Hydroxyproline assay}

We measured collagen content in the lungs with a conventional hydroxyproline assay using a hydroxyproline kit (Keygen Biochemical Institute, Nanjing, China) according to the manufacturer's instructions. The experimental results were quantified using a standard curve of known hydroxyproline concentrations. 
Cell migration assay

The Boyden chamber transwell kit from Corning Company was used to evaluate cell migration ability with modifications as described previously (Raghu et al. 2016). Briefly, AE2 cells were harvested and suspended in serum-free endothelial basal medium containing glipizide at the indicated concentrations. Then, the cell suspension $\left(50 \mu \mathrm{l}, 2.5 \times 10^{4}\right.$ cells $)$ was added to the superior chambers. The inferior chambers were filled with media containing $20 \%$ FBS and various growth factors, including FGF-2, TGF- $\beta$ (R\&D Systems China Co. Ltd.), and msFGFR2c (produced in our own lab). After incubation at $37{ }^{\circ} \mathrm{C}$ for $24 \mathrm{~h}$, cells in the inferior chambers were, stained with $1 \%$ crystal violet for $15 \mathrm{~min}$, and counted using a microscope (ECLIPSE Ti-s; Nikon, Tokyo, Japan) at $\times 40$ magnification.

\section{Photography}

Following histochemical staining, images of the desired regions were obtained using a stereo-fluorescence microscope and processed using the Olympus software package Image-ProPlus 7.0. Mouse lungs were treated by triformol, then treated with OCT mounting medium before sectioned at $10 \mu \mathrm{m}$ using a cryostat microtome (Leica CM1900; Leica, Wetzlar, Germany). Images were obtained using an Olympus IX51 epi-fluorescent microscope (at $\times 200$ and $\times 400$ ) (Olympus, Tokyo, Japan) and analysed using the CW4000 FISH Olympus software.

\section{Histology}

The mouse lungs were fixed in $4 \%$ paraformaldehyde at $4{ }^{\circ} \mathrm{C}$ for $24 \mathrm{~h}$. The lung specimens were then dehydrated, cleared in xylene, embedded in paraffin wax, and serially sectioned at $5 \mu \mathrm{m}$ using a rotary microtome (RM2126RT; Leica). The sections were stained hematoxylin and eosin (H\&E). Airspace volume density was measured using minimum five random images from three samples per group and time point. Masson's staining was used to detect fibrosis in lung sections.
Data analysis

All data analyses were performed using GraphPad Prism 5 (GraphPad Software, La Jolla, CA, USA). The results are presented as mean values \pm standard deviation. All data were analyzed using analysis of variance (ANOVA) or Student's $t$-test to establish differences between the experimental and control groups. Each experiment was repeated three times. $p$ Values less than 0.05 were considered significant.

\section{Results}

msFGFR2c restricted FGF-2-induced or TGF- $\beta$ induced AE2 cell migration in vitro

To investigate whether msFGFR2c affects AE2 cell migration, a transwell assay was performed by $24 \mathrm{~h}$ incubation of AE2 cells with the medium of MRC-5 cells after $48 \mathrm{~h}$ culture (referred to as Med) and various growth factors (Fig. 1a, b). Not only 50\% (Fig. 1a2) and $100 \%$ (Fig. 1a3) Med promoted AE2 cell migration in a dose-dependent manner, but also TGF- $\beta$ and FGF-2 did. However, addition of $320 \mathrm{ng} /$ $\mathrm{mL}$ msFGFR2c (Fig. 1a4) to the culture medium dramatically decreased the number of cells that passed through the wells in Med and TGF- $\beta+$ FGF-2 groups, suggesting that TGF- $\beta$ was important in this prosess, and FGF signal block could neutralize the pro-migratory effects of TGF- $\beta$ and FGF- 2 . The assay (Fig. 1b) also shows that TGF- $\beta$ and FGF-2 can promote AE2 cell migration seperately, and have stronger effect when they are combined. Meanwhile, their effect can both be negated by msFGFR2c, hinted that they all function through FGFR2c. Western blot results showed that CTGF, N-cadherin, and $\alpha$-SMA, all pro-fibrotic factors, in AE2 cells in the presence of Med (Fig. 1c) were all up-regulated, whereas E-cadherin, the epithelial cell marker, was down-regulated (Fig. 1c).

Furthermore, in order to understand the location of a cytokine in the signaling pathway, FGF-2, TGF- $\beta$ and CTGF levels in the MRC-5 cell culture medium were measured by ELISA at $24 \mathrm{~h}$ and $48 \mathrm{~h}$. Nanogram level of TGF- $\beta$ was secreted, which started increasing significantly from the start in a time-dependent manner (Fig. 1d), suggested that TGF- $\beta$ might play a major role. CTGF levels started increasing from the 
a

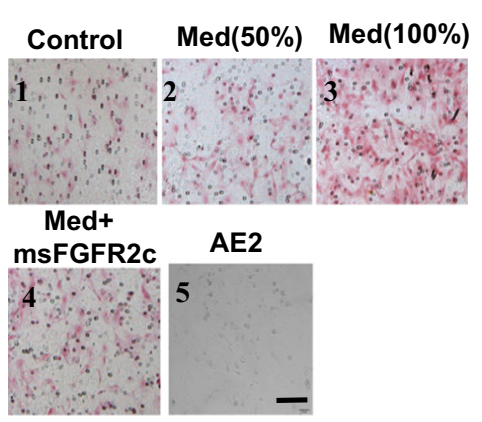

b

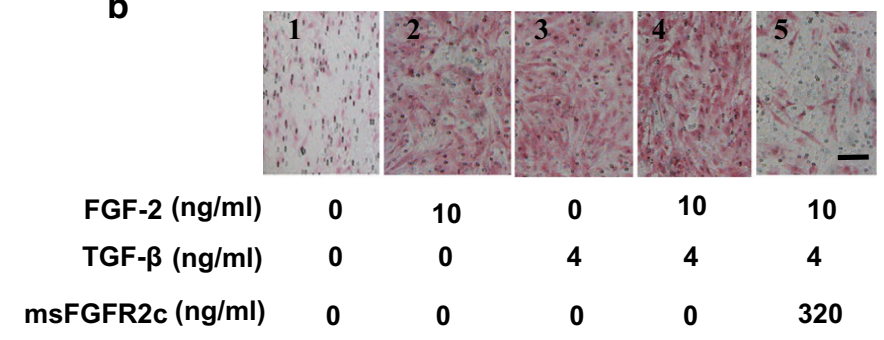

$\begin{array}{llllll}\operatorname{msFGFR2c}(\mathrm{ng} / \mathrm{ml}) & 0 & 0 & 0 & 0 & 320\end{array}$
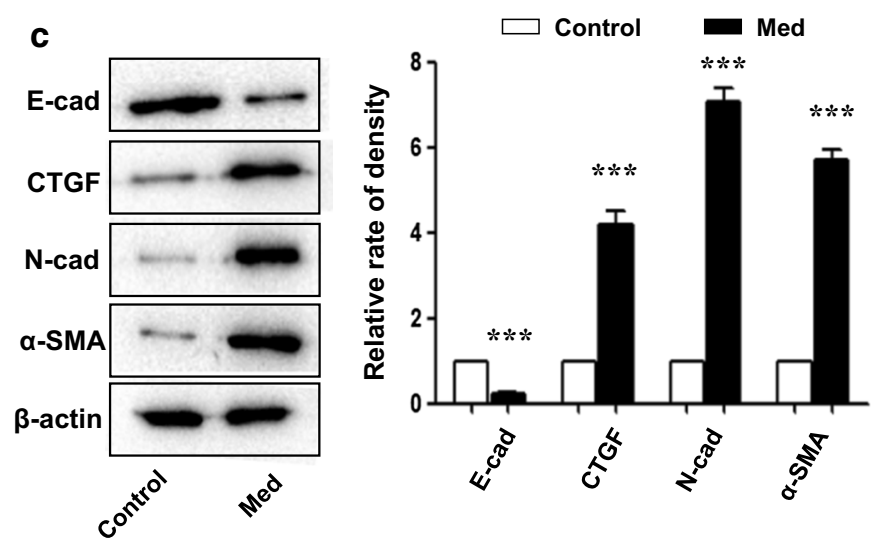

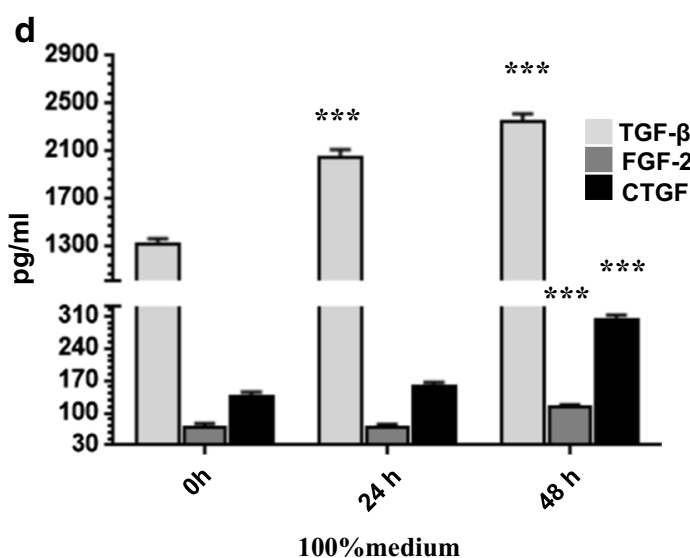

Fig. 1 Determination of alveolar epithelial type II (AE2) cell migration using a transwell assay following exposure to Med (culture medium collected after $48 \mathrm{~h}$ of incubation with MRC-5 cells) and TGF- $\beta$ in combination with msFGFR2c. a Representative crystal violet-stained transwell images for control (a1), 50\% Med-treated (a2), 100\% Med-treated (a3), 100\% Med + $320 \mathrm{ng} / \mathrm{ml}$-treated msFGFR2c (a4)-treated AE2 cells, (a5) on behalf of the AE2 cells under bright-field microscope. b Crystal violet-stained Transwell images of AE2 cells pre-treated for $24 \mathrm{~h}$ with buffer, $10 \mathrm{ng} / \mathrm{ml}$ FGF-2, $4 \mathrm{ng} / \mathrm{ml}$ TGF- $\beta, 10 \mathrm{ng} / \mathrm{ml}$

beginning of the $48 \mathrm{~h}$ incubation period (Fig. 1d), meanwhile FGF-2 level increased later.

All these results indicated that TGF- $\beta$, FGF2 and CTGF secreted by MRC- 5 cells might play important roles in inducing epithelial-to-mesenchymal transition (EMT) in the AE2 cells.

TGF- $\beta$ switched a shift in the FGFR subtypes through CTGF and promoted FGF-2 secretion in AE2 cells, thereby its induction of fibrosis could be blocked by msFGFR2c

The levels of various FGFR subtypes, including FGFR1IIIb, FGFR1IIIc, FGFR2IIIb, and FGFR2IIIc in AE2 cells were determined by real-time PCR after
FGF-2 +4 ng/ml TGF- $\beta, 10$ ng/ml FGF- $2+4$ ng/ml TGF$\beta+320 \mathrm{ng} / \mathrm{ml}$ msFGFR2c. c Western blot data showing the protein levels of E-cadherin, CTGF, N-cadherin, and $\alpha$-SMA in AE2 cells from the control and Med-treated groups. The bar chart shows the ratios of band densities from western blot data. d The bar charts show the levels of TGF- $\beta$, FGF- 2 and CTGF in the MRC-5 cell culture medium at 0,24 , and $48 \mathrm{~h}$. Scale bars $=100 \mu \mathrm{m}$ in $\mathbf{a}$ and $\mathbf{d}$. *Indicates comparison with the control $(* * * \mathrm{p}<0.001)$

the addition of $4 \mathrm{ng} / \mathrm{ml} \mathrm{TGF-} \beta$ or $15 \mathrm{ng} / \mathrm{ml} \mathrm{CTGF}$ for $24 \mathrm{~h}$ (Fig. 2a). According to previous research, CTGF and TGF- $\beta$ both function through FGF signal pathway, which means they need the FGFR2IIIb to FGFR2IIIc subtype switch to function. So we mainly focus on the subtype switch. Compared to the control, there were no obvious alterations in the levels of FGFR1 subtypes induced by TGF- $\beta$ and CTGF. However, FGFR $2 b$ expression was down-regulated and FGFR2c expression was up-regulated by TGF- $\beta$ and CTGF treatment dramatically (Fig. 2a). When siRNA-CTGF was added, it revers the promoting effect of the TGF- $\beta$ on the switching of FGFR2b to FGFR2c. This result suggested that TGF- $\beta$ promoted a shift of the FGFR2 
Fig. 2 The levels of FGF receptor subtypes in AE2 cells in the presence of CTGF, and levels of FGF-2 in AE2 cells following stimulation with either TGF$\beta$ or Med. a Bar chart summarising the RTPCR expression data for FGF receptor subtypes (FGF1IIIb, FGF1IIIc, FGF2IIIb, and FGF2IIIc) in AE2 cells following stimulation with $4 \mathrm{ng} / \mathrm{ml}$ TGF- $\beta, 20 \mathrm{nM}$ siRNACTGF or $15 \mathrm{ng} / \mathrm{ml}$ CTGF for $24 \mathrm{~h}$. b ELISA results showing FGF-2 levels in AE2 cells after $1 \mathrm{~h}$ and $24 \mathrm{~h}$ stimulation with either $4 \mathrm{ng}$ / $\mathrm{ml}$ TGF- $\beta$ or $100 \%$ Med. c ELISA results showing FGF-2 levels in AE2 cells at $24 \mathrm{~h}$ after stimulation with either $15 \mathrm{ng} / \mathrm{ml} \mathrm{CTGF}$ or $25 \mathrm{ng} / \mathrm{ml} \mathrm{CTGF}$. *Indicates comparison with the control; $\uparrow$ indicates comparison with the induced groups $(* * *, \dagger$ $\mathrm{p}<0.001)$

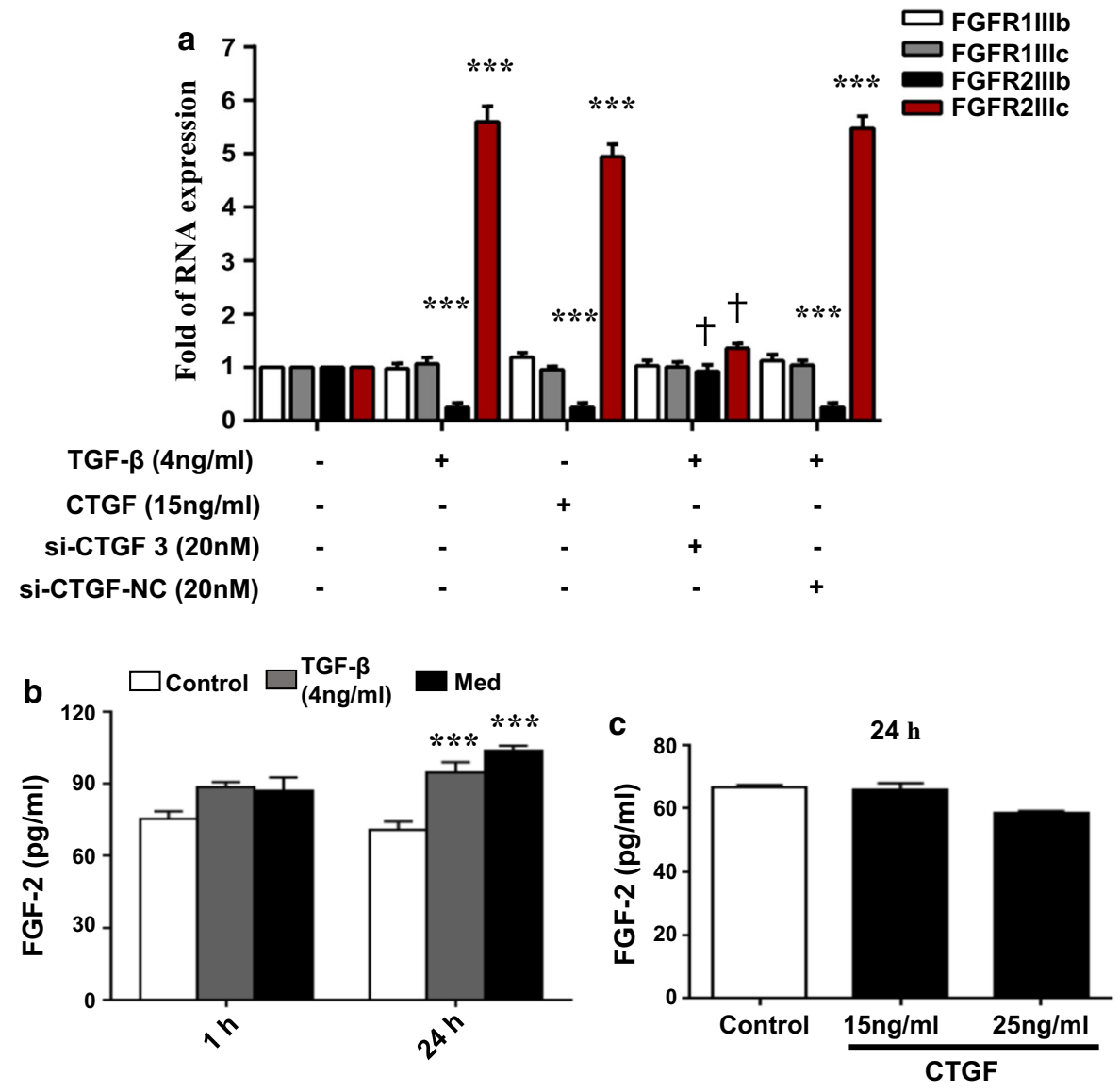

subtype expression from FGFR2b to FGFR2c through CTGF signal pathway.

Furthermore, FGF-2 secretion in the AE2 cell culture medium detected by ELISA (Fig. 2b) increased significantly at $24 \mathrm{~h}$, but not at $1 \mathrm{~h}$, following stimulation with $4 \mathrm{ng} / \mathrm{ml}$ TGF- $\beta$ or $100 \%$ Med (Fig. 2b). Meanwhile, FGF-2 secretion did not change distinctly after the addition of 15 or $25 \mathrm{ng} / \mathrm{ml}$ CTGF in AE2 cells (Fig. 2c) but the inverse was true (Fig. 2b). Therefore, we speculated that the elevation of FGFR2c level induced by TGF- $\beta$ and CTGF made the enhancement of FGF-2 response in AE2 cells, as FGFR2c have the highest affinity with FGF-2 (Mohammadi 2005). Summing-up, FGF-2 signal became dramatically strong and functioned as promoting factor in lung fibrossis.
msFGFR2c application alleviated BLM-induced mouse pulmonary fibrosis

To confirm the anti-fibrotic effect of msFGFR2c in vivo, we established a mouse pulmonary fibrosis model by intratracheal BLM instillation in 10-weekold female mice. In our study, we observed that msFGFR2c treatment significantly reversed the BLMinduced reduction of mouse body weight (Fig. 3a) and increased pulmonary quantity (Fig. 3b) and pulmonary hydroxyproline content (Fig. 3c).

Next, H\&E-stained paraffin sections revealed that BLM treatment induced pulmonary fibrosis beginning from day 10, which showed gradual aggravation (Fig. 4b) compared to the control (Fig. 4a). BLMinduced pulmonary fibrosis was alleviated by msFGFR2c addition (Fig. 4b-c). These morphological observations were supported by the measurement of pulmonary airspace volumes (Fig. 4d). Similarly, we observed a reversal of BLM-induced pulmonary 

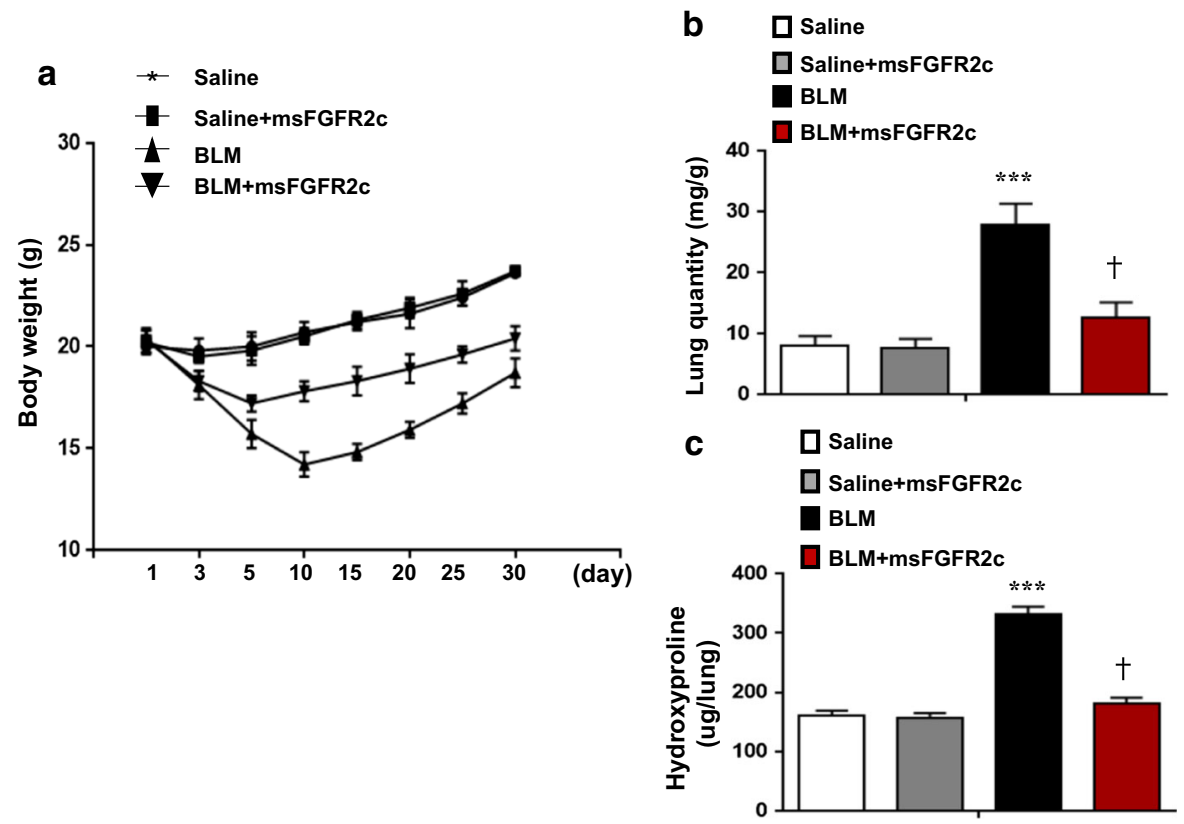

Fig. 3 Effect of msFGFR2c application on bleomycin-induced pulmonary fibrosis. A mouse model for pulmonary fibrosis was established by intratracheal bleomycin (BLM) instillation. a The mouse body weights were measured within 1 month after exposure to BLM, msFGFR2c, or/and saline(as control).

fibrosis upon msFGFR2c treatment in Masson-stained lung sections on days 20 and 30 (Fig. $4 \mathrm{e}-\mathrm{g}$ ).

Furthermore, since pro-SPC is the marker of AE2 cells (Almeida et al. 2013) and high expression of $\alpha$ SMA is the hall-marker of myofibroblasts (Hinz et al. 2003), (the key effector cells in the development of fibrosis), the quantitative expression of pro-SPC and $\alpha$-SMA at the protein level in mouse lungs was used as markers and was determined by western blotting after $\mathrm{BLM}$ or BLM + msFGFR2c administration on different days. After treatment with BLM alone, $\alpha$-SMA expression increased in a time-dependent manner compared to the levels in the corresponding controls, whereas additional treatment with msFGFR2c on day 30 reversed these changes, suggesting that msFGFR2c reverse the fibertic process induced by BLM (Fig. 4h). Pro-SPC levels decreased in the presence of BLM after a combined treatment with msFGFR $2 \mathrm{c}$ on day 30 and gradually returned to normal levels, suggesting that mdFGFR2c prevent the decrease of AE2 cells (Fig. 4h). AE2 cells decreasing is a key feature of the fibrotic process and results above suggests that msFGFR2c could reverse this trend, thus preventing the EMT from being activated. b The pulmonary quantity (pulmonary weight/body weight) was determined for different groups. $\mathbf{c}$ The hydroxyproline contents ( $\mu \mathrm{g} /$ lung) in mouse lungs were determined for different groups. *Indicates comparison with the control. ${ }^{\dagger}$ Indicates comparison with the induced groups $(* * *, \dagger p<0.001)$

\section{Discussion}

The regenerative AE2 cells fail to repopulate the denuded epithelial basal lamina during fibrosis. Though AE2 cells play a key role in lung fibrosis and epithelial regeneration (Knudsen et al. 2017), the precise role of AE2 cells in the fibrotic process and the function of FGF signalling in AE2 cells remain unknown.

Owing to their crucial role in pulmonary fibrosis (Corti et al. 1996; Ehrhardt et al. 2005; Fujino et al. 2011; Liu et al. 2016), mouse primary AE2 cells were examined in this study. Here, we found that the addition of fibroblast medium of MRC-5 cells increased $\mathrm{N}$-cadherin and $\alpha$-SMA levels and decreased E-cadherin levels in AE2 cells (Fig. 1c). Since MRC-5 cell line comes from human being, primary AE2 cells come from mice, we could see TGF- $\beta$, FGF- 2 and CTGF from MRC- 5 cells take their effects on the primary mouse AE2 cells because of the high homology of these cytokines in human and mouse. Though these experiments should be done more strictly in cells from the same species, we just 

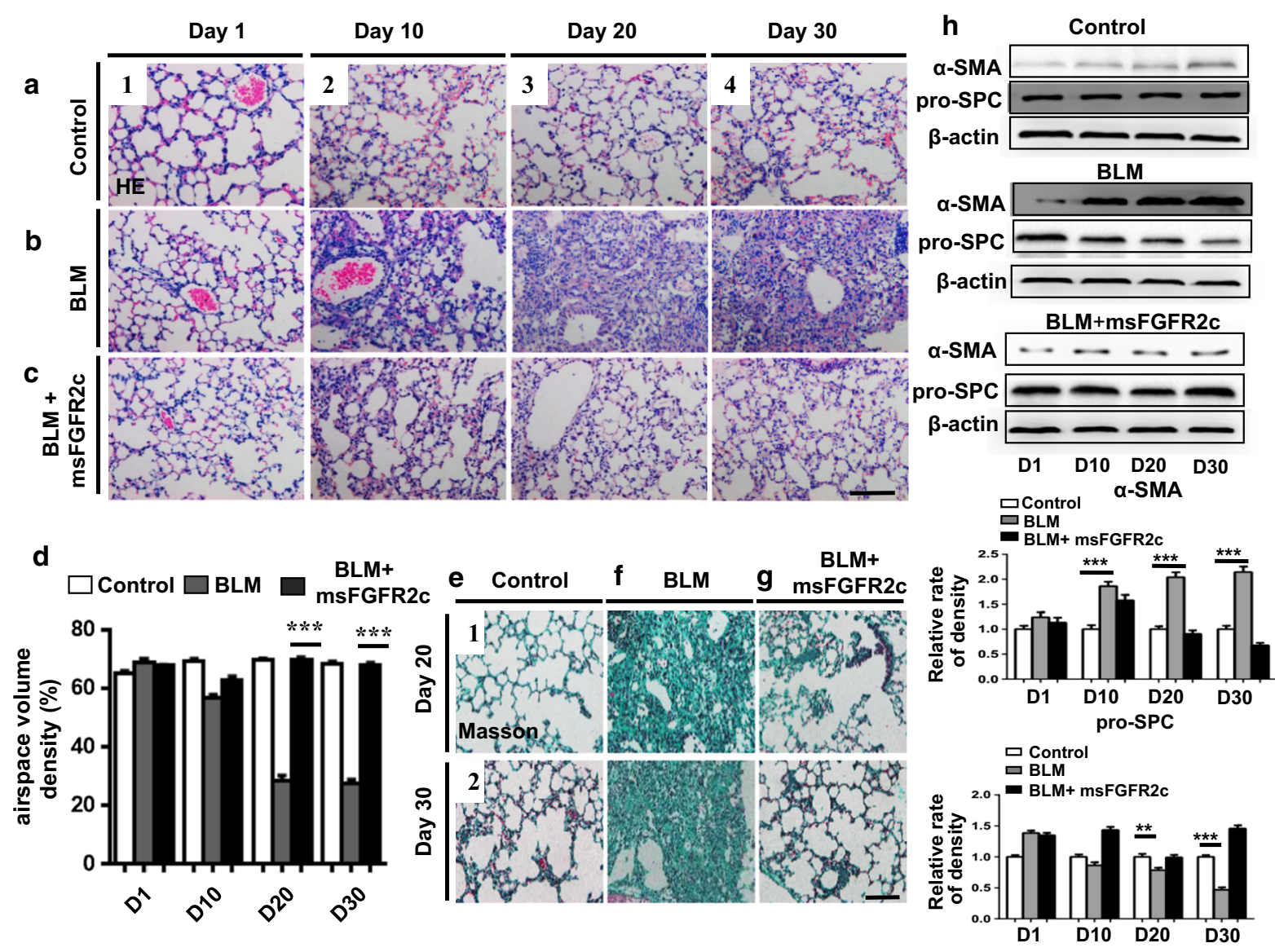

Fig. 4 Mouse pulmonary histology was characterised by haematoxylin and eosin (H\&E) or Masson's trichrome stain in mice treated with bleomycin (BLM) and BLM + msFGFR2c. a-c Representative H\&E-stained lung transverse section images obtained at days 1 (a1), $10(\mathbf{a 2}), 20(\mathbf{a 3})$, and $30(\mathbf{a 4})$ for mice in the control group; days 1 (b1), 10 (b2), 20 (b3), and 30 (b4) for mice in the BLM-treated group; days 1 (c1), 10 (c2), 20 (c3), and 30 (c4), for mice in the BLM + msFGFR2c-treated group. d Bar chart shows the comparison of airspace volume densities among the control, BLM, and BLM + msFGFR2c groups. e-

used mouse primary AE2 cells since human primary AE2 cells was very difficult to be obtained.

Furthermore, msFGFR2c inhibited the pro-fibrotic effect of TGF- $\beta$, FGF-2, or CTGF, suggesting that the role of a shift in FGFR subtypes from FGFR2b to FGFR2c and FGF-2 increase were important for fibrosis (Fig. 3). Thus, FGF-2 signalling pathway activation in AE2 cells might be the key point in the pulmonary fibrotic process.

In the mouse BLM-induced lung fibrotic model, we found msFGFR2c markedly inhibited the fibrotic process. In the msFGFR2c treatment group, the g Representative Masson-stained lung transverse section images obtained at days $20(\mathbf{e 1})$ and $30(\mathbf{e} 2)$ for mice in the control group, days 20 (f1) and 30 (f2) for mice in the BLM-treated group, and days 20 (g1) and 30 (g2) for mice in the BLM + msFGFR2c-treated group. Scale bars $=100 \mu \mathrm{m}$ in $(\mathbf{a}-\mathbf{c})$ and $(\mathbf{e}-\mathbf{g})$. h Western blot data showing the protein levels of pro-SPC and $\alpha$-SMA on the corresponding treatment days for the control, BLM-treated, and BLM + msFGFR2c-treated groups. *Indicates comparison with the control $(* * * p<0.001)$

marker of AE2 cells, pro-SPC, sustained its expressional level, but in the BLM-induced fibrotic group, pro-SPC was down-regulated dramatically in the whole lung-tissue WB assay. These results also suggested the importance of AE2 cells in the repairing of BLM-induced lung wound. Blocking FGF2 signal pathway could inhibit the EMT transition of AE2 cells and further retard lung fibrotic process.

Summing up, we found that TGF- $\beta$ promoted FGF2 expression, triggered FGF receptor subtype $\mathrm{b}$ to $\mathrm{c}$ transition via CTGF, and promoted EMT in AE2 cells. Therefore, msFGFR2c could inhibit the promoting 
effects of TGF- $\beta$, CTGF, and FGF- 2 during lung fibrosis and has the potent clinical value for the treatment of pulmonary fibrosis.

Acknowledgements This work was funded by the National Natural Science Foundation of China (81773330).

\section{Compliance with ethical standards}

Conflict of interest The authors declare no conflict of interest.

Open Access This article is licensed under a Creative Commons Attribution 4.0 International License, which permits use, sharing, adaptation, distribution and reproduction in any medium or format, as long as you give appropriate credit to the original author(s) and the source, provide a link to the Creative Commons licence, and indicate if changes were made. The images or other third party material in this article are included in the article's Creative Commons licence, unless indicated otherwise in a credit line to the material. If material is not included in the article's Creative Commons licence and your intended use is not permitted by statutory regulation or exceeds the permitted use, you will need to obtain permission directly from the copyright holder. To view a copy of this licence, visit http://creativecommons.org/licenses/by/4.0/.

\section{References}

Almeida C, Nagarajan D, Tian J, Leal SW, Wheeler K, Munley M, Blackstock W, Zhao W (2013) The role of alveolar epithelium in radiation-induced lung injury. PLoS ONE 8(1):e53628

Anderson J, Burns HD, Enriquez-Harris P, Wilkie AO, Heath JK (1998) Apert syndrome mutations in fibroblast growth factor receptor 2 exhibit increased affinity for FGF ligand. Hum Mol Genet 7:1475-1483

Byron SA, Pollock PM (2009) FGFR2 as a molecular target in endometrial cancer. Future Oncol 5:27-32

Corti M, Brody AR, Harrison JH (1996) Isolation and primary culture of murine alveolar type II cells. Am J Respir Cell Mol Biol 14:309-315

Demedts M, Costabel U (2002) ATS/ERS international multidisciplinary consensus classification of the idiopathic interstitial pneumonias. Eur Respir J 19:794-796

Ehrhardt C, Kim K-J, Lehr C-M (2005) Isolation and culture of human alveolar epithelial cells. Methods Mol Med 107:207-216

Fujino N, Kubo H, Suzuki T, Ota C, Hegab AE, He M, Suzuki S, Suzuki T, Yamada M, Kondo T et al (2011) Isolation of alveolar epithelial type II progenitor cells from adult human lungs. Lab Invest 91:363-378

Han MK, Murray S, Fell CD, Flaherty KR, Toews GB, Myers J, Colby TV, Travis WD, Kazerooni EA, Gross BH et al (2008) Sex differences in physiological progression of idiopathic pulmonary fibrosis. Eur Respir J 31:1183-1188

Haugsten EM, Wiedlocha A, Olsnes S, Wesche J (2010) Roles of fibroblast growth factor receptors in carcinogenesis. Mol Cancer Res 8:1439-1452
Hinz B, Dugina V, Ballestrem C, Wehrle-Haller B, Chaponnier C (2003) $\alpha$-Smooth muscle actin is crucial for focal adhesion maturation in myofibroblasts. Mol Biol Cell 14(6):2508-2519

Ibrahimi OA, Zhang F, Eliseenkova AV, Itoh N, Linhardt RJ, Mohammadi M (2004) Biochemical analysis of pathogenic ligand-dependent FGFR2 mutations suggests distinct pathophysiological mechanisms for craniofacial and limb abnormalities. Hum Mol Genet 13:2313-2324

Katoh Y, Katoh M (2009) FGFR2-related pathogenesis and FGFR2-targeted therapeutics (review). Int J Mol Med 23:307-311

Kim KK, Kugler MC, Wolters PJ, Robillard L, Galvez MG, Brumwell AN, Sheppard D, Chapman HA (2006) Alveolar epithelial cell mesenchymal transition develops in vivo during pulmonary fibrosis and is regulated by the extracellular matrix. Proc Natl Acad Sci USA 103:13180-13185

Knudsen L, Ruppert C, Ochs M (2017) Tissue remodelling in pulmonary fibrosis. Cell Tissue Res 367(3):607-626

Lee TC, Gold LI, Reibman J, Aston C, Bégin R, Rom WN, Jagirdar J (1997) Immunohistochemical localization of transforming growth factor- $\beta$ and insulin-like growth factor-I in asbestosis in the sheep model. Int Arch Occup Environ Health 69:157-164

Liu Z, Liu G, Zhang GL, Li J, He YQ, Zhang SS, Wang Y, He WY, Cheng GH, Yang X et al (2016) Binding of human recombinant mutant soluble ectodomain of FGFR2IIIc to c subtype of FGFRs: implications for anticancer activity. Oncotarget 18:68473-68488

Matsuda Y, Ueda J, Ishiwata T (2012) Fibroblast growth factor receptor 2: expression, roles, and potential as a novel molecular target for colorectal cancer. Pathol Res Int 2012:574-768

Miyake Y, Kaise H, Isono K, Koseki H, Kohno K, Tanaka M (2007) Protective role of macrophages in noninflammatory lung injury caused by selective ablation of alveolar epithelial type II cells. J Immunol 178:5001-5009

Mohammadi M (2005) Structural basis for fibroblast growth factor receptor activation. Cytokine Growth Factor Rev 16:107-137

Powers CJ, McLeskey SW, Wellstein A (2000) Fibroblast growth factors, their receptors and signaling. Endocr Relat Cancer 7:165-197

Raghu G, Weycker D, Edelsberg J, Bradford WZ, Oster G (2006) Incidence and prevalence of idiopathic pulmonary fibrosis. Am J Respir Crit Care Med 174:810-816

Raghu G, Chen SY, Hou Q, Yeh WS, Collard HR (2016) Incidence and prevalence of idiopathic pulmonary fibrosis in US adults 18-64 years old. Eur Respir J 48:179-186

Robinson PM, Blalock TD, Yuan R, Lewin AS, Schultz GS (2012) Hammerhead ribozyme-mediated knockdown of mRNA for fibrotic growth factors: transforming growth factor-beta 1 and connective tissue growth factor. Methods Mol Biol 820:117-132

Society AT (2000) Idiopathic pulmonary fibrosis: diagnosis and treatment. International consensus statement. American Thoracic Society (ATS) and the European Respiratory Society (ERS). Am J Respir Crit Care Med 161:646-664

Tsuji T, Aoshiba K, Nagai A (2009) Alveolar cell senescence exacerbates pulmonary inflammation in patients with 
chronic obstructive pulmonary disease. Respiration 80:59-70

Wang J, Liu XT, Huang H, Xiao G, Zhou ZY, Chen Y, Yu ZH, He SL, Chen AA, Wang DD et al (2011) Antitumor activity of a recombinant soluble ectodomain of mutant human fibroblast growth factor receptor-2 IIIc. Mol Cancer Ther 10:1656-1666

Wang J, Yu Z, Zhou Z, Huang H, Wang D, Sun L et al (2012) Inhibition of $\alpha$-SMA by ectodomain of FGFR2c to attenuate lung fibrosis. Mol Med 18(6):992-1002

Whitsett JA, Wert SE, Weaver TE (2010) Alveolar surfactant homeostasis and the pathogenesis of pulmonary disease. Annu Rev Med 61:105-119

Yang J, Velikoff M, Canalis E, Horowitz JC, Kim KK (2014) Activated alveolar epithelial cells initiate fibrosis through autocrine and paracrine secretion of connective tissue growth factor. Am J Physiol Lung Cell Mol Physiol 306:786-796

Yu ZH, Wang DD, Zhou ZY, He SL, Chen AA, Wang J (2012) Mutant soluble ectodomain of fibroblast growth factor receptor-2 IIIc attenuates bleomycin-induced pulmonary fibrosis in mice. Biol Pharm Bull 35:731-736

Zhang X, Zhang Y, Tao B et al (2012) Loss of Shp2 in alveoli epithelia induces deregulated surfactant homeostasis, resulting in spontaneous pulmonary fibrosis. FASEB J $26: 2338-2350$

Publisher's Note Springer Nature remains neutral with regard to jurisdictional claims in published maps and institutional affiliations. 